\title{
Health insurance coverage and firm performance: Evidence using firm level data from Vietnam
}

\author{
July 6, 2016 \\ Hiroyuki Yamada ${ }^{\dagger}$ \\ Faculty of Economics, Keio University \\ Tien Manh Vu \\ International Research Fellow of the Japan Society for the Promotion of Science \\ Osaka School of International Public Policy, Osaka University
}

[Key words] Health insurance, Medium and large-scale firms, Propensity-score matching, Vietnam

[JEL Codes] D22, I13, I15, I18, O25

[Abstract]

In literature, there is limited direct evidence regarding the effect of health insurance coverage on firm performance and worker productivity. In this paper, we study the impacts of health insurance on medium and large-scale domestic private firms' performance and productivity in Vietnam, using a large firm level census dataset. We deploy propensity-score matching methods, and find statistically positive health insurance effects on both aggregate profit and profit per worker for both complying and non-complying medium and large-scale firms. Given the full sample results, we recommend an improvement in government monitoring as one of the important policy options to induce medium and large-scale firms to contribute to health insurance premiums for their employees.

$\dagger$ Corresponding author: Hiroyuki Yamada.

2-15-45 Mita, Minato-ku, Tokyo 108-8345, JAPAN.

Tel: +81-(0)3-5427-1271. E-mail: hyamada@econ.keio.ac.jp

[Acknowledgments] We would like to thank Yasuharu Shimamura and Koji Yamazaki for their helpful comments. This research was supported by the Japan Society for the Promotion of Science [Grant-in-Aid for Young Scientists 25780163]. 


\section{Introduction}

How to achieve universal health coverage has become an important policy issue in advanced, emerging, and developing countries alike. For instance, the World Health Organization's (WHO) flagship publication, the World Health Report 2013, focuses entirely on "research for universal health coverage" (WHO 2013). The World Bank also released a report titled "Going universal” (Cotlear et. al. 2015).

Vietnam is not an exception, and the Law on Health Insurance (enacted in 2008) has proposed a grand design and time line to achieve universal health insurance coverage by 2014 . However, the speed of coverage expansion has recently decreased, and the coverage rate was 66\% in 2011 (Vietnam Social Security (VSS) 2012). Moreover, in April 2013, the Viet Nam News (Viet Nam News 2013:05/24/2013) reported that the newly ratified government proposal demonstrates their changed plan to cover about $80 \%$ of the population by 2020 .

One of the bottlenecks against universal health coverage in Vietnam is the low coverage rate among employees of domestic private firms. This group is one of the compulsory groups as defined by the government and has to be provided with health insurance through the domestic private firm they work for. However, compulsory does not mean legally enforceable, and the coverage rate remains at 53.4\% in 2010 (VSS 2011): there were 11.9 million targeted workers in total, but only 6.3 million workers were covered by health insurance. The contribution rate to health insurance was $3 \%$ of the monthly gross salary $(2 \%$ by the employer and $1 \%$ by the employee) until 2009, and was increased to $4.5 \%$ (3\% by the employer and $1.5 \%$ by the employee) in 2010 . 
There are various reasons stemming from various stakeholders on why the health insurance compliance by domestic private firms is far from universal. For instance, the government's ability to enforce the laws is perceived as weak. ${ }^{1}$ Some employers might choose not to provide health insurance to save the money spent on the contribution to health insurance premium. Since the borrowing conditions are not flexible, and accessibility to firm loans is not easy in Vietnam, keeping the unpaid health insurance premium could be a solution to immediately pump more cash into their business. Alternately, employees might be willing to avoid deduction of the contribution to the health insurance premium from their salaries or might think health insurance is not useful. ${ }^{2}$

On the other hand, there are reasons why employers are willing to act as health insurance “agents" for their employees (O'Brien 2003), regardless of the government's weak monitoring ability. Particularly, health insurance may contribute to firms' and workers' productivity, as healthy workers are usually more productive than unhealthy ones. Since workers with health insurance may be more likely to get needed treatment for illnesses and injuries, those with health insurance may be less likely to miss work or miss fewer days of work when they do fall ill.

Given this background, the question whether complying with the health insurance related laws makes complying firms better off or not is ultimately empirical. Surprisingly, there is almost no direct evidence regarding the effect of health insurance coverage on firm performance and worker productivity (O'Brien 2003). Hence, our paper quantifies the effects of complying

\footnotetext{
${ }^{1}$ For instance, the reports of VSS $(2010,2011$, and 2012) do not mention at all penalties in the case a firm does not observe the Law on Health Insurance. Moreover, it is not very clear who is in charge of auditing private firms.

${ }^{2}$ For example, this could be because of the fear that getting reimbursed by health insurance agencies is difficult. Conversely, this could be because of discrimination in terms of public clinic/hospital treatment against health insurance holders. The existence of a voluntary paying system gives priority to patients who pay higher fees in order to get faster access to health services in public clinics/hospitals. The long queue for health checks for health insurance holders with limitedly available facilities and health service prevents employees from holding health insurance.
} 
with the health insurance related laws on firm profit and productivity using a large-scale dataset of domestic private firms in Vietnam.

We believe this study makes a significant contribution to the existing literature because many advanced countries adopt employment-based health insurance, and many developing and emerging countries that consider expanding health insurance coverage mimic the mechanism. Vietnam is one of the leading countries, among developing and emerging, working rigorously towards universal health coverage, including employment-based health insurance. Therefore, our paper provides an informative picture for the case of a developing or emerging country introducing a similar insurance system.

We use the Vietnamese Enterprise Survey (VES) to conduct the analyses. In the survey, the General Statistics Office of Vietnam (GSO) has collected information on economic activities annually since 2001. Specifically, we use cross section data of 2009 because the amount of contribution by a firm to health insurance for employees is available only in the 2009 dataset. $^{3}$ Hence, we use these data to conduct propensity-score matching (PSM). Another feature of our analysis is its focus on medium and large-scale firms. This is because medium and large-scale firms provide more stable employment over longer periods than small and micro firms. Additionally, all domestic private firms with at least 30 employees were surveyed in the VES 2009, implying that we have a census of medium and large-scale private domestic firms in Vietnam, which mitigates sampling biases.

We find positive health insurance effects for both aggregate profit and profit per worker for complying and non-complying medium and large-scale firms. By industry, we find similar

\footnotetext{
${ }^{3}$ In all other years, only the sum of the contribution amounts to health insurance, pension, and unions is available, which makes it difficult for us to judge whether a firm indeed contribute to health insurance premiums for its employees.
} 
positive effects in the construction and wholesale/retail sectors, except insignificant influence in the manufacturing sector.

The rest of this paper is organized as follows: in section 2, we briefly describe the health insurance system in Vietnam; section 3 depicts empirical strategies; section 4 explains the data and reports the first stage probit results; in section 5, we discuss the estimation results; and section 6 concludes the paper.

\section{Background: brief description of the health insurance system in Vietnam and health insurance scheme for non-state owned enterprises}

For health insurance, the Ministry of Finance and the Ministry of Health $(\mathrm{MoH})$ take the initiative, along with the government, and VSS is a governmental policy implementing agency. ${ }^{4}$ Under VSS, the provincial social security offices are followed by the district ones. Under the provision of district social security offices, pay-agents and collection agents are employed. In order to give management advice, the provincial health departments of MoH work together with provincial social security offices. District-level health facilities are also expected to cooperate with provincial and district social security offices.

The foundations of Vietnam's health insurance system were established between 1992 and 1998 in order to achieve improve the health of the population. Figure 1 presents the timeline and the roadmap of health insurance with universal coverage. As for health insurance for workers of private domestic firms, Decree No.299/HDBT was issued by the Council of Ministers in 1992, aiming to cover workers at state owned and non-state owned enterprises with more than 10 workers, as well as pensioners, socially disadvantaged people, and staff of international

\footnotetext{
${ }^{4}$ See Matsushima and Yamada (2014) for the more detailed description.
} 
representative organizations in the country. In 2005, Decree No. 63/2005/ND-CP was introduced for the expansion of compulsory enrolment of workers from non-state owned companies with less than 10 employees. Therefore, these two decrees stipulate all the workers of non-state owned companies, particularly the domestic private firms being in the compulsory group.

One of the notable characteristics of the health insurance system for workers at non-state owned enterprises is that its registration system is individual-based. This means that only the workers are covered by the health insurance provided by the firms, but their family members are not. During the studied period, until 2009, the contribution rate to health insurance was $3 \%$ of the gross income: $2 \%$ by the employer and $1 \%$ by the employee.

The insurance is effective when the insured are provided with medical care at the health facility whose name appears on his/her health insurance card and at higher-level health facilities to which he/she is referred. Patients can choose to register at a health facility of their choice, within the given options by the government (Ministry of Health 2009). In 2009, the co-payments were $20 \%$ for a wage earner when he/she was treated at the medical facility where registered. Many drugs are covered by health insurance, and patients can obtain these drugs at the health facilities at which they are registered. Since health insurance only applies to the purchase of drugs in the hospital where the insured are registered, in many cases, patients cannot obtain the drugs that they need. When patients purchase drugs from a private pharmacy, the costs must be covered out-of-pocket (OOP).

If the insured prefer to be treated at other health facilities, they must pay the hospital directly, and the OOP costs will be reimbursed later at their place of residence, except in emergency cases. In the case of an emergency, treatment will be given free of charge. 


\section{Empirical strategies}

In this section, we estimate the impact of firms' complying with the health insurance related laws on firm performance and productivity, using PSM methods. We estimate average treatment effect on the treated (ATT) and average treatment effect on untreated (ATU). ATT computes the average difference in the outcomes of the firms complying with the health insurance related laws with and without health insurance provision. ATU computes the average difference in outcomes of the firms not complying with the health insurance related laws with and without health insurance provision.

The formula for ATT is given by:

$$
\begin{gathered}
\mathrm{ATT}=\mathrm{E}\left(y_{1 i}-y_{i} \mid D_{i}=1\right) \\
=\mathrm{E}\left(y_{1 i} \mid D_{i}=1\right)-\mathrm{E}\left(y_{0 i} \mid D_{i}=1\right),
\end{gathered}
$$

where $\mathrm{E}(\cdot)$ denotes an expectation operator, $y_{1 i}$ is an outcome of interest for a firm $i$ with health insurance provision to the employees, $y_{0 i}$ is the outcome of the same firm without health insurance provision to the employees, and $D_{i}$ is a treatment indicator equal to 1 if the firm complies with the health insurance related laws (contributes to health insurance premiums for the employees) and 0 otherwise. The fundamental problem with estimating equation (1) is that it is impossible to observe the outcome of firms with health insurance provision for the employees had they not provide health insurance, that is, $\mathrm{E}\left(y_{0 i} \mid D_{i}=1\right)$. Therefore, with observational data, one may be inclined to simply compare outcomes between firms with health insurance provision and those without. However, such an analysis will likely result in biased estimates if the following does not hold: 


$$
\mathrm{E}\left(y_{0 i} \mid D_{i}=1\right)=\mathrm{E}\left(y_{0 i} \mid D_{i}=0\right) .
$$

For our primary estimator, we use PSM, introduced by Rosenbaum and Rubin (1983), with added controls to eliminate the bias because equation (2) does not hold. PSM relies on an assumption of conditional independence, where, conditional on the probability of firm complying with the health insurance related laws given observable covariates, an outcome of interest in the absence of treatment, $y_{0 i}$, and complying with the health insurance related laws, $D_{i}$, are statistically independent. This leads to:

$$
\mathrm{E}\left(y_{0 i} \mid D_{i}=1, p\left(x_{i}\right)\right)=\mathrm{E}\left(y_{0 i} \mid D_{i}=0, p\left(x_{i}\right)\right),
$$

where $p\left(x_{i}\right)$ denotes the probability of the firm contributing to health insurance premiums for the employees given characteristic $x$, which is defined as:

$$
\operatorname{Pr}\left(D_{i}=1 \mid x_{i}\right)=p\left(x_{i}\right) .
$$

Therefore, PSM eliminates the bias that might otherwise result from the selection of observed characteristics.

Another important assumption of PSM is the common support condition, which requires substantial overlap in covariates between firms complying with the health insurance related laws and those not, so that firms being compared have a common probability of being both complying or not.

If these two assumptions are fulfilled, the PSM estimator for ATT can be specified as the mean difference of the firms contributing to health insurance premiums for the employees, matched with those not who are balanced on the propensity scores and fall within the region of common support, expressed as follows: 


$$
A T T_{P S M}=\mathrm{E}\left\{y_{1 i} \mid D_{i}=1, p\left(x_{i}\right)\right\}-\mathrm{E}\left\{y_{0 i} \mid D_{i}=0, p\left(x_{i}\right)\right\}
$$

This PSM estimator yields consistent estimators of the ATT if covariate $x$ properly characterizes the firms providing health insurance. Therefore, selection of $x$ is important. It is recommended that all factors affecting the decision on providing health insurance and outcomes be included (Heckman et. al. 1997, Caliendo and Kopeinig 2008). With similar analogies, we can estimate $A T U_{P S M}$

A key limitation of the PSM method is that if unobservable factors affect the decision of contributing to health insurance premiums for employees, estimated PSM estimators may be biased by the selection of those unobservables (Smith and Todd 2005). CEO's characteristics, which are not available in the data, may play an important role in decision on health insurance provision. Alternatively, it is virtually impossible to control for all relevant unobservables. We therefore test whether unobservables affect estimated results using the sensitivity tests proposed by Rosenbaum (2002).

\section{Data}

We use the data provided by the Vietnamese Enterprise Survey (VES). Since 2001, the General Statistics Office of Vietnam (GSO) has collected information on the economic activities of the preceding year of each business identity countrywide annually. Although the sampling methods are different for each year for private firms, GSO has continued to conduct a census of all private firms with more than 30 employees between 2000 and 2009. There are several complex sampling criteria in 2009 data if the number of employees is less than 30. First, given the rapid increase and the large number of firms, $15 \%$ random sampling was conducted for private firms with less than 30 employees in Hanoi and Ho Chi Minh provinces. Second, 15\% 
random sampling was conducted for private firms with less than 10 employees. Third, in 18 provinces with less than 1,000 firms, a census was conducted regardless of firm size. Fourth, a census was conducted for the following sectors: agriculture, forestry, aquaculture, transportation, hotel, tourism, finance, credit, and insurance. We attempted constructing the corresponding weights, but it was impossible to come up with a convincing set of weights. Therefore, we decided to use only the census of firms having more than 30 employees. By using this sample, our focus is the effects of health insurance on medium and large-scale firms' performance and productivity.

The data set contains information on the total annual contribution amounts to pension, health insurance, and trade-unions. However, the breakdown of these categories is only available in 2009 data. That is, only 2009 data includes the information on whether a firm really contributed to health insurance premiums for its employees. Therefore, we exclusively use the 2009 data. If a firm reports a positive amount contributed to health insurance premiums for employees on the balance sheet, that firm is included in the treatment group. On the other hand, if a firm reports no contribution, the firm is included in the control group. ${ }^{5}$

We define a domestic private firm as a firm not having partial capital from the state or foreign affiliates. We also exclude collective business firms. Additionally, VES contains general information about domestic private firms, such as type of economic activities, profit, output, employment, assets, and liabilities. This information comes directly from the balance sheet. After deleting outliers and observations with missing crucial information, the total sample size of the

\footnotetext{
${ }^{5}$ The problem regarding grouping is tackled in the conclusion section.
} 
domestic private firms whose number of employees is more than 30 is $18,215 .^{6}$ The number of complying firms is 10,827 and that of non-complying firms is 7,388 .

As outcome variables, we use profit after tax deduction and profit after tax deduction per employee. Since the profit could take a negative value, we did not log the profit variables. The unit of measurement is million Vietnamese dong (VND).

As regressors for the first stage probit, we include the debt-asset ratio, log of capital, $\log$ of the number of employees, as well as 23 industry dummies and 63 province dummies. ${ }^{7}$

The descriptive statistics of outcome variables and regressors in the first stage probit are shown in Table 1. The average profit after tax deduction is VND 746.5 million (i.e., USD 43,748.5 in 2009 nominal terms). ${ }^{8}$ The average profit after tax deduction per employee is VND 6.3 million (USD 369.5). These values appear small because there are numerous firms with negative profit after tax deduction. Indeed, more than $10 \%$ of the firms run accounting deficits. In the sample, $59.4 \%$ of the firms contribute to health insurance premiums for their employees. In other words, more than $40 \%$ of the firms do not comply with the health insurance related laws. The average number of employees is approximately $74(=\exp (4.3))$, while the average capital stock is VND 13,696 million (= $\exp (9.525))$. The average debt-asset ratio is 5.568 , with a median just below 2 .

Table 2 reports the unconditional differences in outcome variables and regressors in the first stage probit. Note that outcome variables and firm characteristics are significantly different at the mean between the group of complying firms and that of non-complying firms. In all the variables,

\footnotetext{
${ }^{6}$ The original census of private domestic firms with more than 30 employees is approximately 25,000.

${ }^{7}$ The list of the 23 industries and the sample size for each are shown in Appendix 1.

${ }^{8}$ The official exchange rate in 2009 (annual average based on monthly averages) was VND 17,065.1 per USD (World Bank 2015).
} 
the former group has higher values than the latter, and the differences are large. However, it is unclear in Table 2 whether this reflects favorable profit impacts of health insurance or the exante attributes of complying firms that make them better off than non-complying firms, irrespective of health insurance.

Table 3 reports the estimation results of the first stage probit estimation. The binary dependent variable is equal to 1 if a firm contributes to health insurance premiums and 0 otherwise. We emphasize that the objective of this first stage probit is to balance the important observable covariates underlying health insurance provision between firms complying with health insurance related laws and those not complying, not to establish causal relationships between covariates and contribution to health insurance premiums. We therefore caution against causal interpretation of the results presented in Table 3. For example, subtle forms of endogeneity may affect some covariates. In other words, any endogenous component of these regressors generates a correlation between covariates and the error term akin to the selection-onunobservables problem. Therefore, tests for the robustness of results in the face of prospective selection-on-unobservables provide an effective check on the qualitative impact findings, even if some of the first stage regressors are endogenous. All three main regressors (debt-asset ratio, log of capital, and log of the number of employees) included are statistically significant. Although not shown, many of the province and industry dummies are statistically significant. ${ }^{9}$ Subsequently, the propensity score for each observation is constructed using the parameters obtained by the probit estimation.

\footnotetext{
${ }^{9}$ The full results of the first stage probit are available upon request.
} 


\section{Results}

\subsection{Overall results}

Table 4 reports the PSM estimation results for total profit after tax deduction. As matching algorithms, we use (1) nearest five, (2) radius of 0.01, and (3) a kernel (Epanechnikov kernel, bandwidth is 0.06 ) matching. This is to check whether the results are robust to various matching algorithms. Standard errors are obtained by bootstrapping with 500 replications. For ATT and ATU, we show the results using the mentioned matching algorithms. For each result, we show the result of the balancing and sensitivity tests, the latter of which is proposed by Rosenbaum (2002).

There are several findings. First, looking at the results of ATT, the firms complying with the health insurance related laws become better off rather than those not complying. Specifically, profit increases by VND 293-395 million, depending on the matching algorithm. Subsequently, looking at ATU, we find the positive effect of a firm's contributing to health insurance premiums for the employees on profit for the firms not currently complying with health insurance related laws. As such, profit increases by VND 125-146 million, depending on the matching algorithm. Consequently, the magnitude of ATU is much smaller than that of ATT. However, given that non-complying firms are, on average, small in terms of total profit after tax deduction (VND 278.7 million as per Table 2), the profit gain could be $44.8 \%$ to $52.4 \%$. This implies that these firms could substantially improve their performance if they contribute to health insurance premium for the employees. Combining the results of ATT and ATU, we claim that contributing to health insurance premiums for the employees makes the medium and large-scale firms in Vietnam better off. 
We perform a series of balancing tests on the differences in means to investigate whether the matched non-complying firms have characteristics similar to the matched complying firms in the case of ATT, and whether the matched complying firms have characteristics similar to the matched non-complying firms in the case of ATU. As Table 4 shows, no main variables are statistically different at the $10 \%$ level after matching. The p-values of the likelihood-ratio test of the joint insignificance of all the regressors from the probit estimation of the propensity score show the matching procedures are successful in generating comparison groups to infer the causal impact of health insurance, controlling for observable characteristics.

Table 4 also shows the Rosenbaum bounds test of critical values for each matching estimate to be statistically significant and different from 0 . For instance, the lowest critical value producing a 95\% confidence interval encompassing 0 is 1.2 for all the ATT estimates. Although there is no clear-cut critical threshold that distinguishes the existence and non-existence of hidden bias, the larger the critical value, the less sensitive are the findings based on observables to hidden bias (Rosenbaum 2002). Based on the estimated critical values, we consider our ATU results relatively less sensitive to bias, based on selection-on-unobservables. These facts are very encouraging because they provide relatively solid evidence that currently non-complying firms could become better off by providing health insurance to their employees. However, our ATT results should be interpreted with greater caution because those findings may be sensitive to estimator choice and to the omission of relevant unobserved characteristics of firms.

PSM estimation results for profit after tax deduction per employee are also shown in Table 4. We interpret this as one measure of (labor) productivity. As the results clearly show, the productivity gain is statistically significant for both ATT and ATU. In terms of magnitude, the productivity gain is VND 2.6-3.0 million for the firms complying with health insurance related 
laws and VND 1.6-1.9 million for those not complying. This implies that average labor productivity of medium and large-scale firms increases by contributing to health insurance premiums for the employees. Although the magnitude of ATU (VND 1.6-1.9 million, which corresponds to USD 93.7-111.3) looks small, this gain implies that labor productivity of noncomplying firms increases by $45 \%$ to $54 \%$, since the labor productivity of non-complying firms is much lower than that of complying firms. As for the critical values of the Rosenbaum bounds tests, our ATU results are relatively less sensitive to bias based on selection-on-unobservables, while our ATT results should be interpreted with greater caution because those findings may be sensitive to estimator choice and to the omission of relevant unobserved characteristics of firms.

In summary, although we require caution in interpreting the ATT results due to their sensitivity to selection-on-unobservables, we find positive health insurance effects for both aggregate profit and profit per worker for complying and non-complying medium and large-scale firms. These results are robust in terms of statistical significance, with several matching algorithms under sufficiently balanced samples.

\subsection{Results by industry}

Hitherto, we pool all the industries for estimations. However, impacts of health insurance could be industry specific. Appendix 1 shows the general industrial structure of medium and large-scale firms in terms of the number of firms in Vietnam. Manufacturing, construction, and wholesale/retail are three representative sectors. ${ }^{10}$ Here, we estimate the PSM specifications for

\footnotetext{
${ }^{10}$ The sample of the manufacturing sector consists of industry code 3-10 in Appendix 1.
} 
each of these three groups. ${ }^{11}$ Tables 5, 6, and 7 report the estimation results for the manufacturing, construction, and wholesale/retail sectors, respectively.

In Table 5, we do not find any positive health insurance effect for aggregate profit on both complying and non-complying firms in the manufacturing sector. The estimated effect is not significantly different from 0 either. The effect on the profit per worker is again not different from 0 for complying firms (i.e., ATT), while we find marginal statistically significant positive effects on profit per worker for those not complying with health insurance related laws. However, the estimated effect (ATU) is economically small. One plausible reason on why the results are different for this sector is that the manufacturing sector in Vietnam might be using intensively manual workers who can be easily trained within a few days or weeks. Therefore, the additional profit gain by contributing to health insurance premium is negligible. Alternatively, employers can also replace workers easily because such workers are abundant.

Meanwhile, in both construction (Table 6) and wholesale/retail sectors (Table 7), the positive health insurance effects are statistically significant for both aggregate profit and profit per worker, for complying and non-complying firms. The magnitude of the positive health insurance effects is particularly large for both complying and non-complying firms in the wholesale/retail sector. Therefore, in this sector, complying with the health insurance related laws is profit and productivity enhancing. However, we require caution in interpreting the ATT results due to their sensitivity to selection-on-unobservables. On the other hand, it is encouraging that our ATU results are relatively less sensitive to bias based on selection-on-unobservables, which implies that currently non-complying firms could become better off by contributing to health insurance premiums for their employees.

\footnotetext{
${ }^{11}$ The descriptive statistics for each of the three groups are presented in Appendix 2.
} 


\section{Conclusions and policy implications}

In this paper, we quantify the effects of complying with the health insurance related laws on profit and productivity by using a large-scale dataset of private firms in Vietnam, focusing on medium and large-scale firms. We find positive health insurance effects for both aggregate profit and profit per worker for complying and non-complying medium and large-scale firms.

Given the full sample results, it is recommended that the government encourage medium and large-scale firms to contribute to health insurance premiums for their employees because it is profit and productivity enhancing. Information sharing with non-complying firms (and their employees) so that they would comply is perhaps one effective policy. Additionally, the low compliance rate might be due to weak government monitoring. If this is a case, strengthening the government monitoring could be another policy option.

Although we believe our attempt in this paper is an important initial step toward understanding of effects of health insurance on firms' performance and productivity, many issues remain unsolved. First, we completely ignore small firms in this paper due to the complexity of the VES sampling scheme. However, given that a large number of firms have less than 30 employees, we need to study the health insurance effect on relatively small firms. Second, in future studies, we might have to take into account the issue of partial compliance. In this paper, we classify a firm into the treatment group if the firm has contributed to health insurance premiums. However, some firms might decide to pay health insurance premiums for only a fraction of the employees. Due to data limitations, we could not consider this possibility in this paper, but this issue is an important future research topic. Third, we believe that health insurance effect on employment is an important research area. In this paper, we treat the number of 
employees as a covariate rather than an outcome. However, given the idea that health insurance provision is a type of labor regulation, its employment effect is an important margin to be investigated, particularly if one is interested in the general equilibrium effect. Fourth, in this study, we analyze the health insurance effect as if the supply side of the health sector were given, although provincial dummies are included in the first stage probit. However, the quality of health services people can receive could greatly influence both a firm's decision of contributing to health insurance premiums and effects of health insurance on various margins. We believe a study incorporating the supply side of the health sector would be fruitful. Lastly, we have to mention both internal and external validities. Regarding internal validity, although we examine whether biases based on selection-on-unobservables exist and whether the samples are considered sufficiently balanced, biases could still remain, since our study uses non-experimental data. Regarding external validity, the health insurance system substantially differs across countries. Although we find positive health insurance effects on firm performance and productivity, it is conceivable that such effects differ depending on circumstances. Similar studies in other country contexts are definitely informative.

\section{References}

Caliendo, M., \& Kopeinig, S. (2008). Some practical guidance for the implementation of propensity score matching. Journal of Economic Surveys, 22(1), 31-72.

Cotlear, D., Nagpal, S., Smith, O. K., Tandon, A., Cortez, R. A. (2015). Going universal: how 24 developing countries are implementing universal health coverage reforms from the bottom up. Washington, D.C.: World Bank Group. http://documents.worldbank.org/curated/en/2015/09/25018544/going-universal-24-developing- 
countries-implementing-universal-health-coverage-reforms-bottom-up. Accessed 10 December 2015.

Heckman, J. J., Ichimura, H., \& Todd, P. E. (1997). Matching as an econometric evaluation estimator: Evidence from evaluating a job training programme. The Review of Economic Studies, 64(4), 605-654.

Matsushima, M., \& Yamada, H. (2014). Public health insurance in Vietnam towards universal coverage: identifying the challenges, issues, and problems in its design and organizational practices. Journal of International Health, 29(4), 289-297.

Ministry of Health. 2009. BẢO HIỂM XÃ HỘI TỈNH BÌNH DƯƠNG. Danh sách khám chữa bệnh 64 tỉnh thành. [online] Available at<http://www.bhxhbinhduong.gov.vn/Danh-mucco-so-KCB-ban-dau->. Accessed 10 October 2012.

O'Brien, E. (2003). Employers' benefits from workers' health insurance. Milbank Quarterly, 81(1), 5-43.

Rosenbaum, P. R. (2002). Observational studies (pp. 1-17). Springer, New York.

Rosenbaum, P. R., \& Rubin, D. B. (1983). The central role of the propensity score in observational studies for causal effects. Biometrika, 70(1), 41-55.

Smith, J. A., \& Todd, P. E. (2005). Does matching overcome LaLonde's critique of nonexperimental estimators?. Journal of Econometrics, 125(1), 305-353.

Viet Nam News (2013) Health insurance project goal: $80 \%$ coverage by 2020. [Internet] VSS. Available at: http://vietnamnews.vn/society/237645/health-insurance-for-all-projectapproved.html (Accessed: 24 May 2013) 
Vietnam Social Security (VSS) (2010). Vietnam Social Security Annual Report. Hanoi, VSS.

Vietnam Social Security (VSS) (2011). Vietnam Social Security Annual Report. Hanoi, VSS.

Vietnam Social Security (VSS) (2012). Vietnam Social Security Annual Report. Hanoi, VSS.

World Health Organization (2013). World health report 2013: Research for universal health coverage. World Health Organization, Luxembourg.

World Bank (2015). World Development Indicators. http://data.worldbank.org/datacatalog/world-development-indicators. Accessed 6 April 62016. 
Figure 1: Timeline and roadmap of health insurance universal coverage

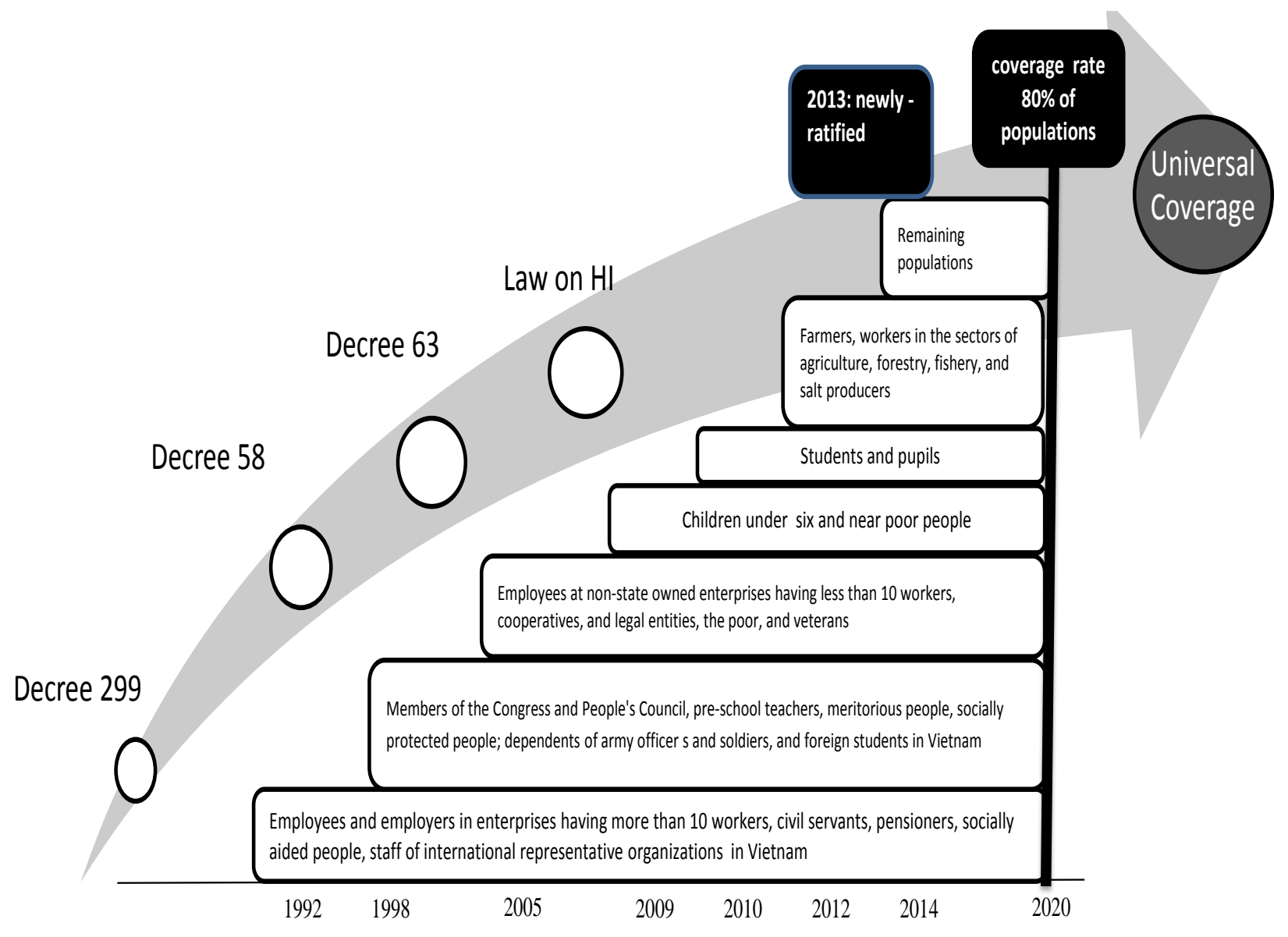

Source: Matsushima and Yamada (2014) 
Table 1: Descriptive statistics of (A) outcome variables and (B) a dependent variable and regressors in the first stage probit

\begin{tabular}{lll}
\hline Variable & \multicolumn{1}{c}{ Mean } & Std. Dev. \\
\hline $\begin{array}{l}\text { Outcome variables } \\
\text { Aggregate profit after tax deduction (million VND) }\end{array}$ & 746.573 & $2,777.870$ \\
$\quad$ Profit after tax deduction per employee (million VND) & 6.307 & 21.046 \\
$\begin{array}{l}\text { Whether a firm pays health insurance premium for the employees } \\
\text { (=1 for paying firms and 0 otherwise.) }\end{array}$ & 0.594 & 0.491 \\
$\begin{array}{l}\text { Regressors in the first stage probit } \\
\text { ln (the number of employees) }\end{array}$ & 4.307 & 0.722 \\
$\quad \begin{array}{lc}\text { ln (capital, million VND) } \\
\text { debt-asset ratio }\end{array}$ & 9.525 & 1.296 \\
Sample size & 5.568 & 10.359 \\
\hline
\end{tabular}

Note: 24 industry and 63 province dummies are omitted. 
Table 2: Mean difference in outcome variables and regressors in the first stage probit

\begin{tabular}{lrrr}
\hline & $\begin{array}{c}\text { With health } \\
\text { insurance }\end{array}$ & $\begin{array}{c}\text { Without health } \\
\text { insurance }\end{array}$ & Difference \\
\hline Variable & & & \\
Outcome variables & & & \\
Aggregate profit after tax deduction & $1,065.790$ & 278.765 & 787.025 \\
$\quad$ (million VND) & $(3,370.920)$ & $(1416.050)$ & $(41.512)^{* * *}$ \\
Profit after tax deduction per employee & 8.185 & 3.554 & 4.630 \\
$\quad$ (million VND) & $(24.039)$ & $(15.247)$ & $(0.315)^{* * *}$ \\
Regressors in the first stage probit & & & \\
ln (the number of employees) & 4.461 & 4.081 & 0.381 \\
& $(0.755)$ & $(0.601)$ & $(0.010)^{* * *}$ \\
ln (capital, million VND) & 9.874 & 9.014 & 0.860 \\
& $(1.245)$ & $(1.194)$ & $(0.018)^{* * *}$ \\
debt-asset ratio & 5.835 & 5.175 & 0.660 \\
& $(10.219)$ & $(10.548)$ & $(0.660)^{* * *}$ \\
Sample size & 10,827 & 7,388 & \\
\hline
\end{tabular}

Notes

1: Standard deviations are in parentheses for means and standard errors are in parentheses for the difference in mean. $* * * \mathrm{p}<0.01$.

2: 24 industry and 63 province dummies are omitted. 
Table 3: First stage probit estimation result

\begin{tabular}{ll}
\hline Variables & \\
\hline $\ln$ (the number of employees) & $0.323^{* * *}$ \\
& {$[0.018]$} \\
$\ln$ (capital, million VND) & $0.284^{* * *}$ \\
& {$[0.010]$} \\
debt-asset ratio & $-0.003^{* * *}$ \\
& {$[0.001]$} \\
Constant & $-4.915^{* * *}$ \\
& {$[0.218]$} \\
Industry dummy & Yes \\
Province dummy & Yes \\
Prob > chi2 & 0.000 \\
Pseudo R2 & 0.175 \\
Observations & 18,215 \\
\hline
\end{tabular}

Notes

1: Dependent variable $=1$, if a firm pays health insurance premiums for the employees and 0 otherwise.

2: Robust standard errors in brackets. $* * * \mathrm{p}<0.01, * * \mathrm{p}<0.05, * \mathrm{p}<0.1$. 
Table 4: Estimated ATT and ATU (Full samples)

\begin{tabular}{|c|c|c|c|c|c|c|}
\hline & \multicolumn{3}{|l|}{ ATT } & \multicolumn{3}{|l|}{ ATU } \\
\hline & Nearest 5 & Radius of 0.01 & Kernel $^{\mathrm{a}}$ & Nearest 5 & Radius of 0.01 & Kernel $^{\mathrm{a}}$ \\
\hline \multicolumn{7}{|l|}{ Aggregate profit after tax deduction } \\
\hline Estimated ATT/ATU (million VND) & 292.916 & 339.820 & 395.070 & 124.907 & 138.838 & 146.126 \\
\hline Standard error ${ }^{\mathrm{b}}$ & $(103.550)^{* * *}$ & $(89.930)^{* * *}$ & $(74.526)^{* * *}$ & $(26.786)^{* * *}$ & $(23.286)^{* * *}$ & $(24.536)^{* * *}$ \\
\hline \multicolumn{7}{|l|}{ Sensitivity test } \\
\hline Rosenbaum bounds critical level & 1.2 & 1.2 & 1.2 & 1.6 & 3.1 & 3.4 \\
\hline \multicolumn{7}{|l|}{ Profit after tax deduction per employee } \\
\hline Estimated ATT/ATU (million VND) & 2.665 & 2.845 & 3.013 & 1.643 & 1.797 & 1.904 \\
\hline Standard error ${ }^{\mathrm{b}}$ & $(0.585)^{* * *}$ & $(0.498) * * *$ & $(0.466)^{* * *}$ & $(0.406) * * *$ & $(0.336)^{* * *}$ & $(0.370)^{* * *}$ \\
\hline \multicolumn{7}{|l|}{ Sensitivity test } \\
\hline Rosenbaum bounds critical level & 1.2 & 1.2 & 1.2 & 1.5 & 2.8 & 3.0 \\
\hline \multicolumn{7}{|l|}{ Balancing test } \\
\hline \multicolumn{7}{|l|}{$\mathrm{t}$-value on the difference in means } \\
\hline ln (the number of employees) & -0.33 & 0.14 & 1.59 & 1.31 & 0.84 & 1.22 \\
\hline $\ln ($ capital) & -1.22 & -0.99 & 0.5 & 0.66 & 0.90 & 1.12 \\
\hline debt-asset ratio & -0.71 & -0.73 & -0.82 & 0.75 & 0.50 & 0.56 \\
\hline P-values of the likelihood-ratio test & 0.572 & 0.968 & 0.883 & 0.402 & 0.793 & 0.994 \\
\hline
\end{tabular}

Notes

$* * * \mathrm{p}<0.01, * * \mathrm{p}<0.05, * \mathrm{p}<0.10$

a: We use an Epanechnikov kernel with bandwidth of 0.06 .

b: Standard errors are obtained by bootstrapping with 500 replications. 
Table 5: Estimated ATT and ATU (Manufacturing sector)

\begin{tabular}{|c|c|c|c|c|c|c|}
\hline & \multicolumn{3}{|l|}{ ATT } & \multicolumn{3}{|l|}{ ATU } \\
\hline & Nearest 5 & Radius of 0.01 & Kernel $^{\mathrm{a}}$ & Nearest 5 & Radius of 0.01 & Kernel $^{\mathrm{a}}$ \\
\hline \multicolumn{7}{|l|}{ Aggregate profit after tax deduction } \\
\hline Estimated ATT/ATU (million VND) & -146.499 & -138.793 & 56.438 & 74.459 & 67.932 & 71.392 \\
\hline Standard error ${ }^{\mathrm{b}}$ & $(260.029)$ & $(231.243)$ & $(178.320)$ & $(60.210)$ & $(49.267)$ & $(49.030)$ \\
\hline \multicolumn{7}{|l|}{ Sensitivity test } \\
\hline Rosenbaum bounds critical level & - & - & - & - & - & - \\
\hline \multicolumn{7}{|l|}{ Profit after tax deduction per employee } \\
\hline Estimated ATT/ATU (million VND) & 0.151 & 0.274 & 0.96 & 0.947 & 0.829 & 0.877 \\
\hline Standard error ${ }^{\mathrm{b}}$ & $(1.291)$ & $(1.136)$ & $(0.965)$ & $(0.514)^{*}$ & $(0.449)^{*}$ & $(0.439)^{* *}$ \\
\hline \multicolumn{7}{|l|}{ Sensitivity test } \\
\hline Rosenbaum bounds critical level & - & - & - & 1.4 & 1.9 & 2.2 \\
\hline \multicolumn{7}{|l|}{ Balancing test } \\
\hline \multicolumn{7}{|l|}{$\mathrm{t}$-value on the difference in means } \\
\hline $\ln$ (the number of employees) & -1.52 & 1.33 & -0.34 & $1.76^{*}$ & 1.63 & 1.51 \\
\hline $\ln ($ capital) & -0.27 & -0.25 & 0.67 & -1.26 & -1.09 & -0.59 \\
\hline debt-asset ratio & 0.25 & 0.32 & -0.03 & -0.57 & 0.18 & -0.15 \\
\hline P-values of the likelihood-ratio test & 0.683 & 0.973 & 0.989 & 0.941 & 0.995 & 1.000 \\
\hline
\end{tabular}

Notes

The sample size is 5,892 (3,725 complying and 2,167 non-complying firms).

$* * * \mathrm{p}<0.01, * * \mathrm{p}<0.05, * \mathrm{p}<0.10$

a: We use an Epanechnikov kernel with bandwidth of 0.06 .

b: Standard errors are obtained by bootstrapping with 500 replications. 


\begin{tabular}{|c|c|c|c|c|c|c|}
\hline & \multicolumn{3}{|l|}{ ATT } & \multicolumn{3}{|l|}{ ATU } \\
\hline & Nearest 5 & Radius of 0.01 & Kernel $^{\mathrm{a}}$ & Nearest 5 & Radius of 0.01 & Kernel $^{\mathrm{a}}$ \\
\hline \multicolumn{7}{|l|}{ Aggregate profit after tax deduction } \\
\hline Estimated ATT/ATU (million VND) & 355.822 & 372.562 & 341.966 & 113.607 & 127.16 & 121.454 \\
\hline Standard error ${ }^{\mathrm{b}}$ & $(79.613)^{* * *}$ & $(71.161)^{* * *}$ & $(75.140)^{* * *}$ & $(38.580)^{* * *}$ & $(30.266) * * *$ & $(28.215) * * *$ \\
\hline \multicolumn{7}{|l|}{ Sensitivity test } \\
\hline Rosenbaum bounds critical level & 1.2 & 1.2 & 1.2 & 2.0 & 3.2 & 3.7 \\
\hline \multicolumn{7}{|l|}{ Profit after tax deduction per employee } \\
\hline Estimated ATT/ATU (million VND) & 2.446 & 2.521 & 2.282 & 1.643 & 1.736 & 1.649 \\
\hline Standard error ${ }^{b}$ & $(0.782)^{* * *}$ & $(0.658)^{* * *}$ & $(0.703)^{* * * *}$ & $(0.685)^{* *}$ & $(0.578)^{* * *}$ & $(0.518) * * *$ \\
\hline \multicolumn{7}{|l|}{ Sensitivity test } \\
\hline Rosenbaum bounds critical level & 1.2 & 1.2 & 1.2 & 1.9 & 3.1 & 3.8 \\
\hline \multicolumn{7}{|l|}{ Balancing test } \\
\hline \multicolumn{7}{|l|}{$\mathrm{t}$-value on the difference in means } \\
\hline $\ln$ (the number of employees) & 1.01 & 1.52 & 1.09 & 0.25 & 0.09 & 0.35 \\
\hline $\ln ($ capital) & 0.06 & -0.21 & 0.09 & 1.08 & 0.31 & 0.81 \\
\hline debt-asset ratio & 0.96 & 0.46 & 0.35 & -0.54 & -0.16 & -0.24 \\
\hline P-values of the likelihood-ratio test & 0.98 & 0.997 & 1.000 & 1.000 & 1.000 & 1.000 \\
\hline
\end{tabular}

Notes

The sample size is 4,810 (2,517 complying and 2,293 non-complying firms).

$* * * \mathrm{p}<0.01, * * \mathrm{p}<0.05, * \mathrm{p}<0.10$

a: We use an Epanechnikov kernel with bandwidth of 0.06 .

b: Standard errors are obtained by bootstrapping with 500 replications. 
Table 7: Estimated ATT and ATU (Wholesale/retail sector)

\begin{tabular}{|c|c|c|c|c|c|c|}
\hline & \multicolumn{3}{|l|}{ ATT } & \multicolumn{3}{|l|}{ ATU } \\
\hline & Nearest 5 & Radius of 0.01 & Kernel $^{\mathrm{a}}$ & Nearest 5 & Radius of 0.01 & Kernel $^{\mathrm{a}}$ \\
\hline \multicolumn{7}{|l|}{ Aggregate profit after tax deduction } \\
\hline Estimated ATT/ATU (million VND) & 668.749 & 632.029 & 619.060 & 308.694 & 311.683 & 288.621 \\
\hline Standard error ${ }^{\mathrm{b}}$ & $(157.819)^{* * *}$ & $(140.954)^{* * *}$ & $(134.940)^{* * *}$ & $(93.808) * * *$ & $(77.536)^{* * *}$ & $(72.753)^{* * *}$ \\
\hline \multicolumn{7}{|l|}{ Sensitivity test } \\
\hline Rosenbaum bounds critical level & 1.3 & 1.2 & 1.2 & 1.6 & 2.5 & 2.6 \\
\hline \multicolumn{7}{|l|}{ Profit after tax deduction per employee } \\
\hline Estimated ATT/ATU (million VND) & 6.341 & 5.703 & 5.446 & 4.311 & 4.818 & 4.223 \\
\hline Standard error ${ }^{\mathrm{b}}$ & $(1.814)^{* * *}$ & $(1.634)^{* * *}$ & $(1.549)^{* * *}$ & $(1.526)^{* * *}$ & $(1.399)^{* * *}$ & $(1.178)^{* * *}$ \\
\hline \multicolumn{7}{|l|}{ Sensitivity test } \\
\hline Rosenbaum bounds critical level & 1.3 & 1.2 & 1.2 & 1.6 & 2.5 & 2.6 \\
\hline \multicolumn{7}{|l|}{ Balancing test } \\
\hline \multicolumn{7}{|l|}{$\mathrm{t}$-value on the difference in means } \\
\hline $\ln$ (the number of employees) & 0.08 & -0.33 & 0.35 & 0.48 & 0.14 & 0.50 \\
\hline $\ln ($ capital) & -0.34 & -0.66 & -0.07 & 0.24 & 0.53 & 0.07 \\
\hline debt-asset ratio & -0.61 & -0.8 & -0.34 & -0.34 & 0.05 & -0.16 \\
\hline P-values of the likelihood-ratio test & 1.000 & 1.000 & 1.000 & 1.000 & 1.000 & 1.000 \\
\hline
\end{tabular}

Notes

The sample size is 2,828 ( 1,863 complying and 965 non-complying firms).

$* * * \mathrm{p}<0.01, * * \mathrm{p}<0.05, * \mathrm{p}<0.10$

a: We use an Epanechnikov kernel with bandwidth of 0.06.

b: Standard errors are obtained by bootstrapping with 500 replications. 
Appendix 1: List of 23 industries

\begin{tabular}{lll}
\hline & Number of firms & Percent \\
\hline 1-Agriculture, forestry, and aquaculture & 324 & 1.78 \\
2-Mining and quarrying & 423 & 2.32 \\
3-Food and drink & 1,121 & 6.15 \\
4-Textile and garment & 1,022 & 5.61 \\
5-Shoes and leather & 190 & 1.04 \\
6-Wood, wood products, and printing & 1,096 & 6.02 \\
7-Chemical, chemical products, and pharmaceutical & 290 & 1.59 \\
8-Rubber, rubber products, and plastic & 447 & 2.45 \\
9-Non-metal & 924 & 5.07 \\
10-Metal & 802 & 4.4 \\
11-Others (electric equip, machinery, repairing, installation) & 1,146 & 6.29 \\
12-Accommodation and food service & 602 & 3.3 \\
13-Arts, entertainment, and recreation & 35 & 0.19 \\
14-Construction & 4,810 & 26.41 \\
15-Education & 95 & 0.52 \\
16-Electricity, gas, steam, and air conditioning supply & 33 & 0.18 \\
17-Information and communication & 117 & 0.64 \\
18-Professional, scientific, and technical activities & 564 & 3.1 \\
19-Transportation and storage & 1,160 & 6.37 \\
20-Water supply, sewerage waste management and remediation & 48 & 0.26 \\
21-Wholesale and retail trade & 2,828 & 15.53 \\
22-Other service activities & 30 & 0.16 \\
23-Others & 108 & 0.59 \\
\hline Total & 18,215 & 100
\end{tabular}


Appendix 2: Mean difference in outcome variables and regressors in the first stage probit

With health Without health

insurance insurance

Difference

(1) Manufacturing Sector

Outcome variables

Aggregate profit after tax deduction (million VND)

$1,311.302$

348.650

962.652

Profit after tax deduction per employee (million VND)

$(3,927.862)$

$(1,995.621)$

7.604

2.836

$(90.652)^{* * *}$

(21.914)

(14.238)

4.768

Regressors in the first stage probit

$\ln$ (the number of employees)

4.627

4.153

$(0.525)^{* * *}$

ln (capital, million VND)

(0.791)

(0.662)

0.474

9.889

8.858

$(0.020)^{* * *}$

(1.285)

debt-asset ratio

3.428

(1.284)

1.031

(6.341)

3.874

$(0.034)^{* * *}$ 3,725

$(8.399)$

$-0.446$

Sample size

2,167

(2) Construction Sector

Outcome variables

Aggregate profit after tax deduction

750.207

$(2,395.577)$

6.010

Profit after tax deduction per employee (million VND)

Regressors in the first stage probit

ln (the number of employees)

ln (capital, million VND)

debt-asset ratio

Sample size

(3) Wholesale/Retail sector

Outcome variables

Aggregate profit after tax deduction (million VND)

Profit after tax deduction per employee (million VND)

Regressors in the first stage probit

ln (the number of employees)

ln (capital, million VND)

debt-asset ratio

Sample size

\section{Notes}

2,517

(1.194)

8.298

(12.219)
186.607

(604.172)

2.717

(8.196)

4.141

(0.604)

8.988

(1.082)

6.852

(12.232)

2,293

1: Standard deviations are in parentheses for means, and standard errors are in parentheses for the difference in mean.

$2: * * * \mathrm{p}<0.01, * * \mathrm{p}<0.05$

3: 24 industry and 63 province dummies are omitted. 